УДК 538.9

DOI: $10.17308 / \mathrm{kcmf} .2019 .21 / 1158$

Поступила в редакцию 27.06.2019

Подписана в печать 15.09.2019

\title{
ВНЕДРЕНИЕ СЕРЕБРА В МАТРИЦУ ПОРИСТОГО КРЕМНИЯ МЕТОДОМ ЭЛЕКТРО-ТЕРМОДИФФУЗИИ
}

\author{
(c2019 В. Л. Кошевой ${ }^{1}$, А. О. Белорус ${ }^{2}$, Л. Б. Матюшкин ${ }^{2}$, \\ И. М. Плешанов ${ }^{3}$, П. В. Середин ${ }^{4}$, С. А. Ивков ${ }^{4}$, А. С. Леньшин ${ }^{4 \bowtie}$ \\ ${ }^{1}$ Санкт-Петербургский горный университет \\ Васильевский остров, 21 линия, 2, 199106 Санкт-Петербург, Российская Федерация \\ ${ }^{2}$ Санкт-Петербургский государственный электротехнический университет «ЛЭТИ» \\ им. В. И. Ульянова (Ленина) \\ ул. Профессора Попова, 5, 197376 Санкт-Петербург, Российская Федерация \\ ${ }^{3}$ Санкт-Петербургский национальный исследовательский университет информационных технологий, \\ механики и оптики \\ Кронверкский пр., 49, 197101 Санкт-Петербург, Российская Федерация \\ ${ }^{4}$ Воронежский государственный университет \\ Университетская пл., 1, 394018 Воронеж, Российская Федерация
}

\begin{abstract}
Аннотация. В работе были проведены исследования возможности внедрения серебра в пористый кремний методом электро-термодиффузии и установлено влияние процедуры осаждения на адсорбционные свойства поверхности пористой матрицы. Композиты пористого кремния с внедренными частицами металла относятся к многофункциональным материалам и перспективны для применения в современной оптоэлектронике, сенсорике и персонализированной медицине.
\end{abstract}

Ключевые слова: кремний, пористый кремний, композитные структуры, функционализация, электро-термодиффузия, угол смачивания.

\section{ВВЕДЕНИЕ}

В настоящее время активно ведутся междисциплинарные исследования многофункциональных композитных материалов, в том числе для целей персонализированной медицины, оптики, сенсорики. Одним из подходов формирования таких материалов является создание пористых биосовместимых матриц с осажденными каталитически активными частицами различных металлов. В качестве осаждаемого металла в зависимости от целей исследования могут выступать серебро, золото, магнитные металлы группы железа, олово, индий, цинк и их оксиды. Пористый кремний (por-Si) с осажденными частицами серебра, благодаря широкому набору подстраиваемых под конкретную практическую задачу характеристиками, может применяться в качестве элементов фотодетекторов, солнечных батарей [1], медицинских микроустройств (имплантов) с антимикробным эффек-

$\triangle$ Леньшин Александр Сергеевич, e-mail: lenshinas@phys.vsu.ru том [2], а также при создании электрохимических сенсоров [3-4].

Цель работы было установление возможности внедрения серебра в пористый кремний методом электро-термодиффузии и влияния процедуры осаждения на адсорбционные свойства поверхности пористой матрицы. Исследуемые структуры могут быть использованы в сенсорных устройствах в качестве механически прочной контактной базы (электродов).

\section{ЭКСПЕРИМЕНТАЛЬНАЯ ЧАСТЬ \\ Методика синтеза пористых структур на основе кремния (por-Si)}

В работе для формирования пористых структур на основе кремния (por-Si) с осажденным $\mathrm{Ag}$ использовался метод электрохимического травления $[5,6]$. Установка для получения образцов пористого кремния состоит из стеклоуглеродного тигля с электролитом, в который помещается образец. Стеклоуглеродный тигель при анодировании выступает в роли катода. В качестве электролита в работе был ис-

Контент доступен под лицензией Creative Commons Attribution 4.0 License.

The content is available under Creative Commons Attribution 4.0 License. 
пользован водный раствор на основе фтороводородной кислоты (HF) с добавлением изопропилового спирта $\left(\mathrm{C}_{3} \mathrm{H}_{7} \mathrm{OH}\right)$.

Для формирования пористой матрицы были выбраны монокристаллические подложки кремния, легированные фосфором ( $n$-типа проводимости), кристаллографическим направлением (100), удельным сопротивлением $4.5 \mathrm{Ohm} \cdot \mathrm{cm}$. Так же в процессе травления соблюдались определённые технологические параметры: время анодирования $t=10 \mathrm{~min}$, плотность тока $j=30 \mathrm{~mA} / \mathrm{cm}^{2}$. Полученные в ходе электрохимического травления пористые матрицы в дальнейшем применялись в качестве подложек для создания структур por-Si/Ag .

\section{Синтез коллоидных квантовых точек} с использованием нитрата серебра $\mathrm{AgNO}_{3}$

Функционализация матрицы пористого кремния проводилась наночастицами $\mathrm{AgNO}_{3} \mathrm{c}$ применением метода электро-термодиффузии. Под функционализацией подразумевается процесс формирования композитных структур на основе por-Si c измененными по сравнению с оригинальной матрицей структурными и физико-химическими свойствами. Для синтеза чернил серебра был применен метод коллоидных квантовых точек. Подобный синтез в органической неполярной среде позволяет варьировать лиганды, находящиеся на поверхности частиц, что определяет условия смешиваемости поверхности раствором. Установка для синтеза наночастиц серебра представлена в работе [7].

Для формирования конечного раствора производилось смешивание нитрата серебра, цитрата натрия, хлорида натрия и $95^{\circ} \mathrm{C}$ раствора аскорбиновой кислоты. Далее нагрев поддерживался в течение 30 минут до полного протекания реакции. Для избавления от непрореагировавших компонентов проводилось центрифугирование коллоидного раствора. В работах $[7,8]$ показано, что по данной методике получения наночастиц нитрат серебра распадается до металлического Ag, а нераспавшиеся реагенты удаляются центрифугированием.

На основе данных сканирующей электронной микроскопии (рис. 1), был определён диаметр частиц $20 \mathrm{~nm}[7]$.

Далее синтезированные наночастицы серебра также с помощью метода центрифугирования были нанесены на слои пористого кремния с последующим отжигом при температуре $150{ }^{\circ} \mathrm{C}$ в течение 30 минут.

\section{Метод электро-термодиффузии}

Стандартными методами формирования контактов (ионно-плазменное распыление, ме- тод термического испарения и т. д.) сложно обеспечить качественное введение наночастиц на глубину в пористую матрицу. С этой целью был применен метод электро-термодиффузии, при котором частицы Ag могут активно проникать в поры. В работе для реализации процессов электро-термодиффузии использовалась установка, включающая в себя: муфельную печь, способную поддерживать температуру в пределах от 100 до $900{ }^{\circ} \mathrm{C}$, источник напряжения с рабочим диапазоном в районе 100-400 V и прижимной механизм, реализующий электрический контакт с экспериментальным образцом.

Перед проведением электро- и термодиффузии на образцы пористого кремния предварительно был нанесен слой серебра. Образцы были помещены в муфельную печь. После достижения температуры в $200{ }^{\circ} \mathrm{C}$ на образец подавалась разность потенциалов в $300 \mathrm{~V}$ в течение 25 минут. Стоит отметить, что образцы при данном технологическом процессе подвергаются низкотемпературному отжигу, что в свою очередь приводит к модификации морфологии и физических характеристик исследуемых структур.

\section{РЕЗУЛЬТАТЫ И ИХ ОБСУЖДЕНИЕ}

\section{Методы исследования структур}

Для исследования композитных структур на основе пористой матрицы кремния с частицами серебра был использован растровый электронный микроскоп TESCAN MIRA3. Данный метод позволил выявлять особенности морфологии пористых матриц до и после функционализации. Также для определения особенностей процессов функционализации методом растекающейся капли был рассчитан угол смачивания.

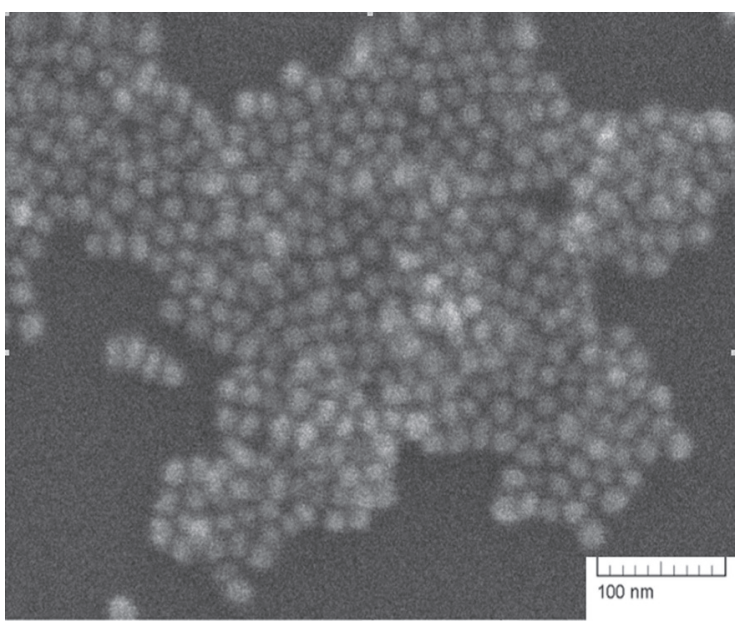

Рис. 1. Данные сканирующей электронной микроскопии наночастиц серебра [7]

[Fig. 1. Scanning electron microscopy data of silver nanoparticles [7]] 
В. Л. Кошевой, А. О. Белорус, Л. Б. Матюшкин, И. М. Плешанов... Внедрение серебра в матрицу пористого кремния...

\section{Растровая электронная микроскопия}

Данные растровой электронной микроскопии исходных образцов por-Si приведены на рис. 2-3.

Анализируя РЭМ снимки, можно утверждать, что размер пор для образца марки КЭФ-4.5 составляет $d=50-100 \mathrm{~nm}$ с толщиной слоя до $20 \mu \mathrm{m}$, особенности морфологии на сколе связаны с кристаллографической ориентацией пластины [9]. Данные РЭМ для пористых матриц кремния после нанесения на них слоя серебра методом синтеза коллоидных квантовых точек представлены на рис. 3.

По данным РЭМ (рис. 3) было выявлено, что серебро присутствует преимущественно на поверхности пористой матрицы кремния. Также на боковом срезе можно установить, что небольшая концентрация серебряных частиц способна по- падать внутрь пор, но данный механизм не является определяющим при сцеплении пористой матрицы со слоем серебра.

\section{Исследование композитных структур на основе матрицы por-Si/Ag после процесса электро-термодиффузии методом растровой электронной микроскопии}

На рис 4. представлены РЭМ-изображения образцов с нанесенным серебром после процедуры электро-термодиффузии.

По данным данных РЭМ (рис. $4 a, b)$ серебро активно диффундирует в поры, заполняя практически всю внутреннюю поверхность. При приложении напряжения и воздействии температуры происходит втягивание частиц вглубь пористого слоя. Серебро, диффундируя в поры, повышает удельную площадь поверхности металли-

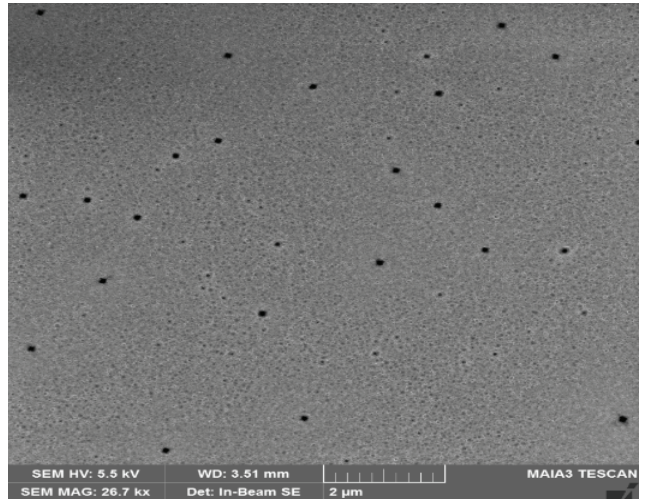

$a$

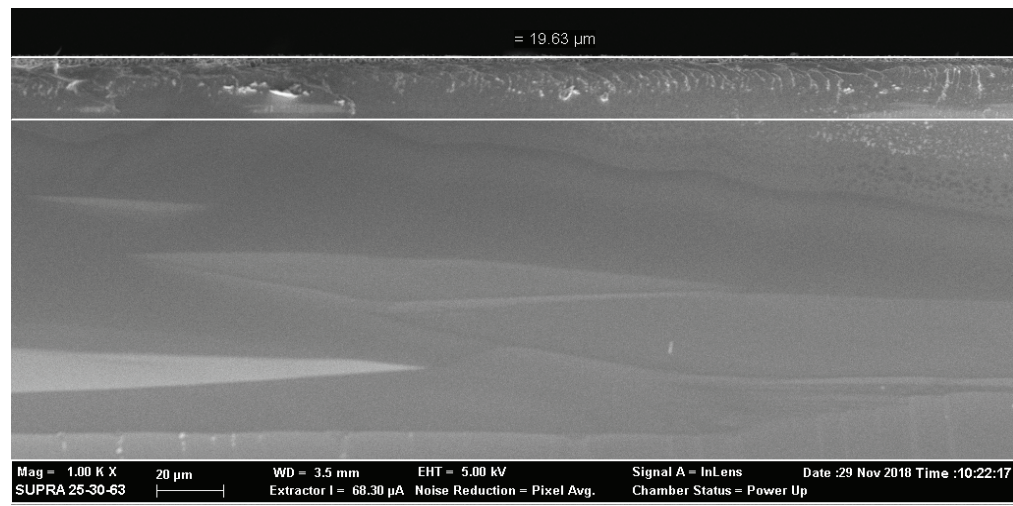

$b$

Рис. 2. Данные растровой электронной микроскопии por-Si: $a$ - РЭМ поверхности образца; $b$ - РЭМ поперечного сечения образца

[Fig. 2. SEM data of silicon porous structures: $a$-surface; $b$ side cut]

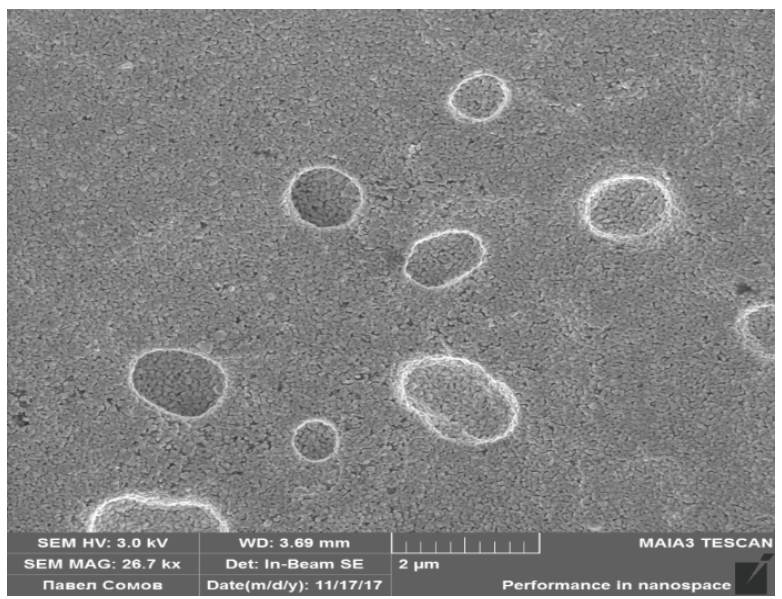

a

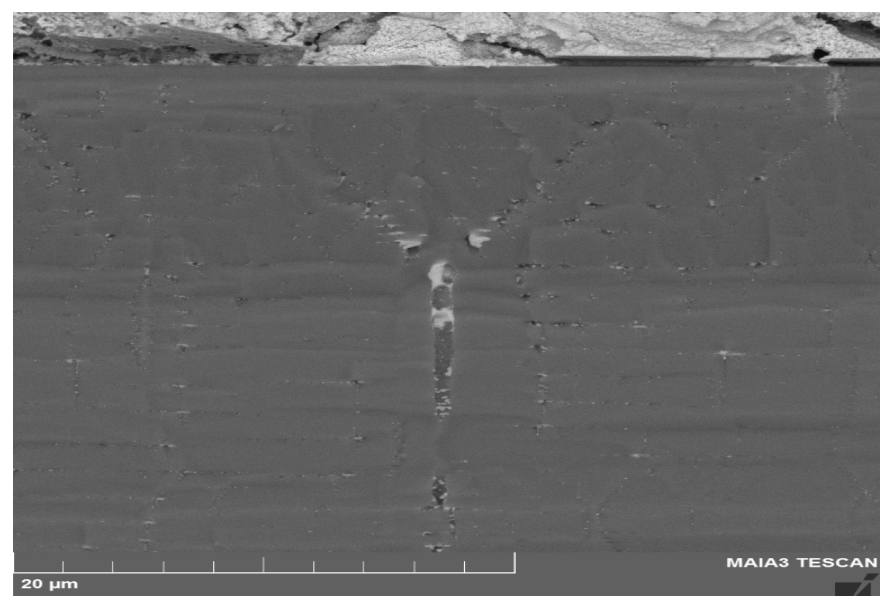

$b$

Рис. 3. Данные растровой электронной микроскопии por-Si/Ag: $a$ - РЭМ поверхности образца; $b$ - РЭМ поперечного сечения образца

[Fig. 3. SEM data of porous silicon structures with a deposited silver layer: $a$ - surface; $b$ - side cut of pores] 


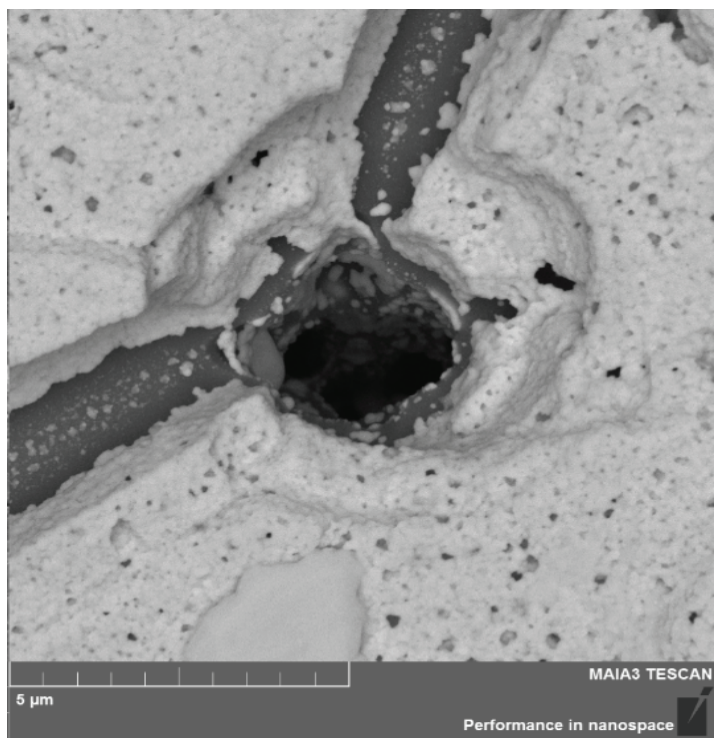

$a$

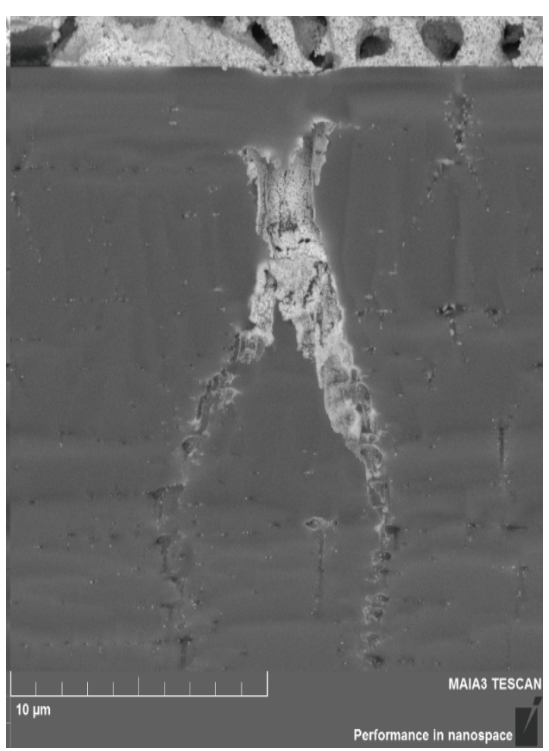

$b$

Рис. 4. Данные растровой электронной микроскопии por-Si/Ag после процесса электро-термодиффузии: $a$ - РЭМ поверхности образца; $b$ - РЭМ поперечного сечения образца [Fig. 4. SEM data of por-Si with a deposited silver layer after the process of electro-thermal diffusion: $a$ - surface; $b$ - side cut]

ческого слоя, и увеличивается качество закрепления посредством перехода к диффузионным процессам. Данный процесс можно охарактеризовать как эффект перераспределения серебра на поверхности при электро- термодиффузионном воздействии.

\section{Исследование структур методом рентгеновской дифракции}

Структурная диагностика полученных образцов проводилась методом рентгеновской дифракции, с использованием дифрактометра

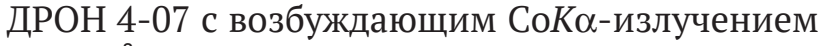
(1.789 ̊̊)в одном режиме (рис. 5).

На дифрактограмме подложки пористого кремния наблюдаются линии Si (200) на $2 \theta=38.5^{\circ}$, а также $\mathrm{Si}(400) \mathrm{Kb}$ на $73.3^{\circ}$ и $\mathrm{Si}(400) \mathrm{Ka}$ на $82.4^{\circ}$ соответственно. С учетом приборной погрешности и возможного влияния пористого слоя полуширина линий $\mathrm{KaKb}$ и их соотношение остается постоянным и соответствует параметрам подложки кристаллического кремния.

На дифрактограммах образцов с осажденными частицами серебра наблюдаются линии, соответствующие металлическому серебру $\mathrm{Ag}(111)$ на $44.5^{\circ}, \operatorname{Ag}(200)$ на $52.3^{\circ}$ и $\mathrm{Ag}(220)$ на $76.8^{\circ}$. После проведения процедуры электро-термодиффузии линии серебра, в особенности $\mathrm{Ag}(111)$, на дифрактограмме проявляются менее интенсивно, при этом полуширина линии $\mathrm{Ag}(111)$ растет. Это может быть вызвано изменением морфо- логии образцов и уменьшением среднего размера частиц.

\section{Метод краевого угла смачивания}

Методом измерения краевого угла смачивания в данной работе были определены характеристики гидрофильности/гидрофобности поверхности полученных в работе образцов. Изменение краевого угла смачивания поверхности образцов после проведения с ними каких-либо действий может свидетельствовать как об изменении морфологии, так и об изменении состава адсорбционных кислотно-основных функциональных центров на поверхности образцов, характеризующих физико- химические свойства материала.

На слои por-Si до процесса функционализации наночастицами серебра и после механическим дозатором были нанесены одинаковые водные капли, после чего полученные изображения фиксировались. Измерительный стенд представляет собой закрепленный микроскоп с горизонтальной оптической осью, расположенной в одной плоскости с исследуемым образцом. Для дальнейшей обработки полученных изображений был разработан виртуальный прибор в программной среде LabVIEW [10]. Принцип работы виртуального прибора заключается в том, что программа, обрабатывая изображение, получает данные о диаметре и высоте капли и производит расчет краевого угла смачивания методом 


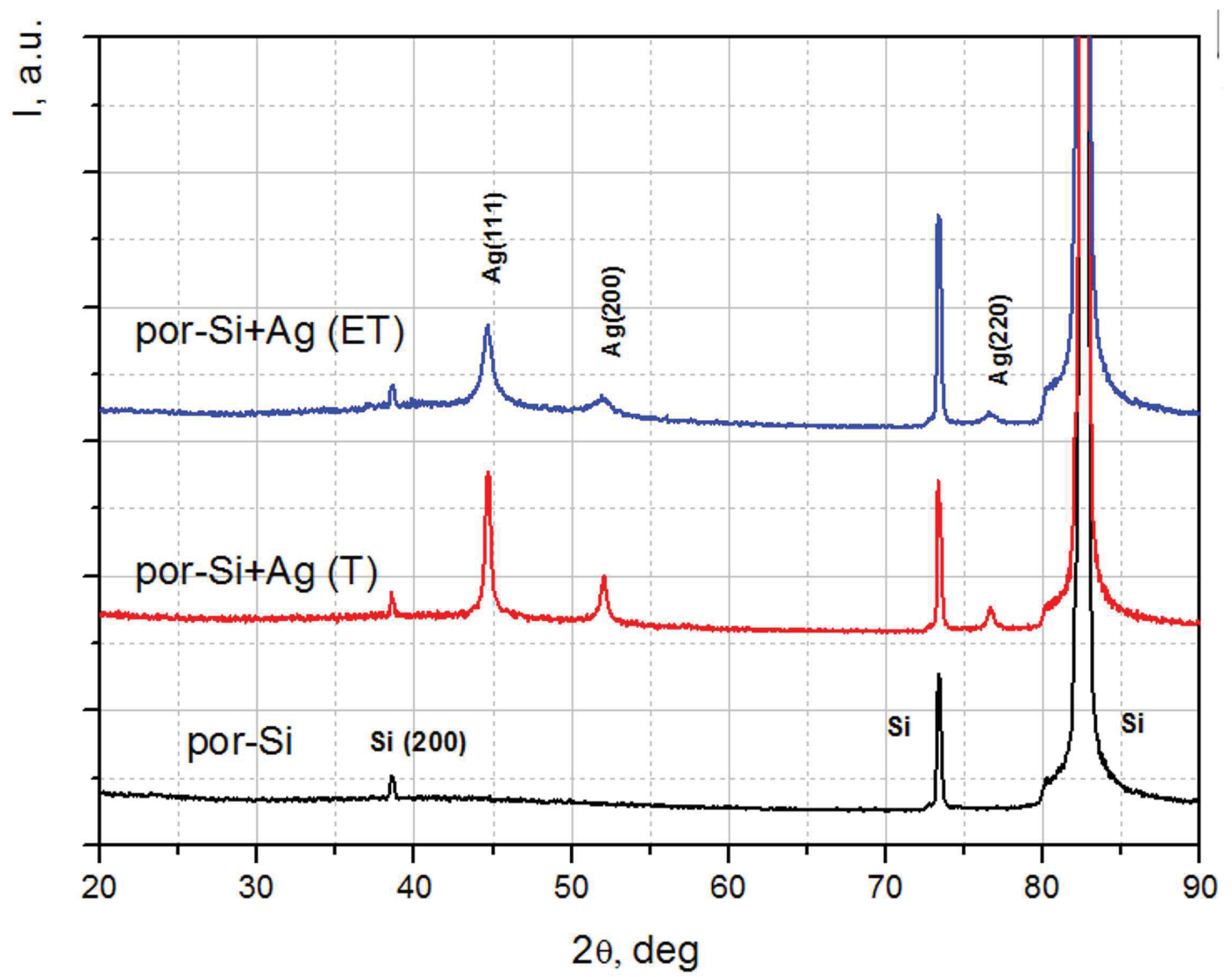

Рис. 5.XRD-спектры исходного пористого кремния, por-Si c нанесенным Ag (T) и por-Si c нанесенным Ag после процедуры электро-термодиффузии (ET)

[Fig. 5. XRD-spectra of the initial porous silicon, por-Si with deposited Ag and por-Si with deposited Ag after the electrothermodiffusion procedure]

«проекции капли». Точность расчета угла по данной методике оценивается в 1-5 градусов, контрольные измерения краевого угла смачивания при помощи средств стандартного графического редактора подтвердили корректность работы программного обеспечения. Данные, полученные по описанной методике, приведены на рис. $6 a, b, c$ и в табл. 1.

Определение угла смачивания является методом контроля процессов функионализации.

Табл. 1. Данные угла смачивания

[Tabl. 1.Wetting angle data]

\begin{tabular}{|c|c|}
\hline $\begin{array}{c}\text { Образец } \\
\text { [Sample] }\end{array}$ & $\begin{array}{c}\text { Угол смачива- } \\
\text { ния } \\
\text { [Wettingangle] } \theta, \\
\text { размерность, } \\
{\left[\begin{array}{c}\text {, value, }^{\circ}{ }^{\circ}\end{array}\right.}\end{array}$ \\
\hline$a-$ por-Si & 59 \\
\hline$b-$ por-Si/Ag & 31 \\
\hline $\begin{array}{c}c-\text { por-Si/Ag с применение } \\
\text { электро-термодиффузии } \\
\text { [using electro-thermal diffusion] }\end{array}$ & 42 \\
\hline
\end{tabular}

Пористая матрица кремния изначально склонна к гидрофобности $\left(\theta \approx 59^{\circ}\right)$, рис. $5 a$. Далее при нанесении частиц серебра гидрофобность сменяется на гидрофильность $\left(\theta \approx 31^{\circ}\right)$, рис. $5 b$, и после использования метода электро-термодиффузии угол смачивания и характер гидрофильности меняются слабо $\left(\theta \approx 42^{\circ}\right)$, рис. 5 с. Увеличение краевого угла смачивания при нанесении наночастиц серебра может быть связано как с изменением морфологии поверхности образца, так и с изменением поверхностных функциональных групп вследствие пассивации поверхности пористого кремния. Процесс электро-термодиффузии позволяет осуществлять перераспределение наночастиц серебра с поверхности пористого кремния в глубь образца, что в свою очередь приводит к уменьшению толщины слоя наночастиц серебра и как следствие изменению свойств поверхности, что приводит к незначительному росту краевого угла смачивания.

\section{ЗАКЛЮЧЕНИЕ}

В работе продемонстрирована эффективность применения методики электро-термодиф- 


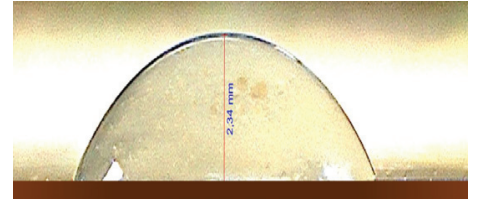

$a$

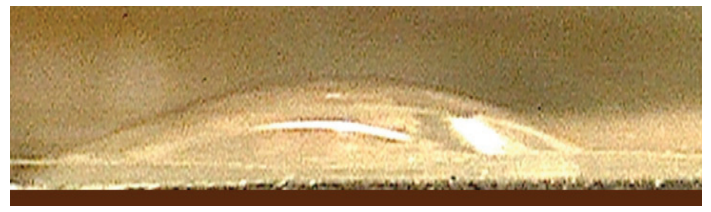

$b$

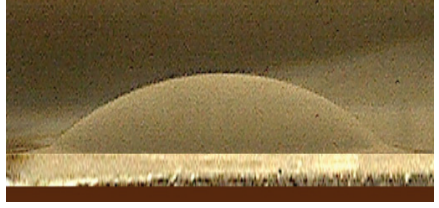

c

Рис. 6. Расчёт угла смачивания для образцов: $a$ - por-Si; $b$ - por-Si/Ag; $c$ - por-Si/Ag с применением электро-термодиффузии

[Fig. 6. Calculation of the wetting angle for samples: $a$ - por-Si; $b$ - por-Si/Ag; $c$ - por-Si/Ag with the use of electro-thermal diffusion]

фузии для внедрения серебра в матрицу пористого кремния. Для синтеза чернил нитрата серебра $\mathrm{AgNO}_{3}$ был применен метод коллоидных квантовых точек. Размер наночастиц составлял порядка $20 \mathrm{~nm}$. С помощью метода центрифугирования слой серебра был нанесен на пористую матрицу кремния с последующим отжигом. В результате электротермодиффузии наночастицы серебра активно диффундировали в пористую матрицу, образуя композитную структуру.

На основе данных полученных методикой определения краевого угла смачивания были сделаны выводы о том, что пористая матрица кремния изначально склонна к гидрофобности $\left(\theta \approx 59^{\circ}\right)$. После нанесения частиц серебра гидрофобность сменяется на гидрофильность. По сравнению с аналогичными методами $[11,12]$ данный технологический процесс позволяет наносить наночастицы серебра в глубь матрицы пористого кремния, тем самым создавая активный проводящий слой. Исследуемая композитная структура может найти широкое применение в сенсорах различного типа, выступая в роли электродной базы, на которую может наноситься (фото-, био- и т. д) активный слой. Также создаваемые электроды должны иметь повышенную стабильность и механическую прочность за счёт формирования диффузионного соединения.

\section{ИСТОЧНИК ФИНАНСИРОВАНИЯ}

Исследование выполнено при поддержке РФФИ в рамках научного проекта 19-32-50038 мол_нр «Исследование морфологических, физико-химических и оптических свойств матриц на основе por-Si в зависимости от методов их формирования и функционализации».

\section{КОНФЛИКТ ИНТЕРЕСОВ}

Авторы декларируют отсутствие явных и потенциальных конфликтов интересов, связанных с публикацией настоящей статьи.

\section{СПИСОК ЛИТЕРАТУРЫ}

1. Raúl J. Martín-palma, Patrick D. McAtee, Rehab Ramadan, Akhlesh Lakhtakia. Hybrid nanostructured porous silicon-silver layers for wideband optical absorption // Scientific Reports, 2019, v. 9(1), p. 7291. DOI: $10.1038 /$ s41598-019-43712-7

2. Kleps I., Miu M., Danila M., Simion M., Ignat T., Bragaru A., Dumitru L., Teodosiu G. Silver/porous silicon (PS) nanocomposite layers for biomedical applications //“2006 International Semiconductor Conference”, 27-29 Sep., 2006, no. 9211112. DOI: 10.1109/ SMICND.2006.283935

3. Ensafi A. A., Rezaloo F., Rezaei B. Electrochemical sensor based on porous silicon/silver nanocomposite for the determination of hydrogen peroxide // Sensors and Actuators B, 2016, v. 231, pp. 239-244. DOI: 10.1016/j.snb.2016.03.018

4. Jinjie Yin, Xiang Qi, Liwen Yang, Guolin Hao, Jun Li, Jianxin Zhong A hydrogen peroxide electrochemical sensor based on silver nanoparticles decorated silicon nanowire arrays // Electrochimica Acta, 2011, v. 56(11), pp. 3884-3889. DOI: 10.1016/j.electacta.2011.02.033

5. Спивак Ю. М., Беспалова К. А., Белорус А. О., Паневин А. А., Сомов П. А., Григорьева Н. Ю., Чистякова Л. В., Журавский С. Г., Мошников В. А. Способ получения и пример лекарственной функционализации поверхности наночастиц пористого кремния // Биотехносфера, 2017(3), с. 69-75.

6. Pastukhov A. I., Belorus A. O., Bukina Ya. V., Spivak Yu. M., Moshnikov V.A. Influence of technology conditions on the surface energy of porous silicon using the method of contact angle // Proc. of "2017 IEEE Conference of Russian Young Researchers in Electrical and Electronic Engineering (EIConRus)", 13 Feb., 2017, pp. 1183-1185. DOI: 10.1109/ eiconrus.2017.7910770

7. Матюшкин Л. Б. Технология и оборудование для получения коллоидных квантовых точек $\mathrm{CsPbX}_{3}(\mathrm{X}=\mathrm{Cl}, \mathrm{Br}, \mathrm{I}), \mathrm{CdSe} / \mathrm{ZnS}$, плазмонных наночастиц $\mathrm{Ag} / \mathrm{SiO}_{2}$ и гибридных структур на их основе. Дисс. ... канд. тех. наук. Санкт-Петербург, 2018, 138 c. URL: https://elibrary.ru/item.asp?id=35115356 
8. Permiakov N.V., Matyushkin L. B., Belorus A. O., Koshevoi V. L. Investigation of a program-controlled process of impregnation of porous semiconductors with silver nanoparticles to create an electrical contact // Proc. of "IEEE Conference of Russian Young Researchers in Electrical and Electronic Engineering (EIConRus)", 2018, pp. 539-543. DOI: 10.1109/EIConRus.2018.8317154

9. Травкин П. Г., Воронцова Н. В., Высоцкий С. А., Леньшин А. С., Спивак Ю. М., Мошников В.А. Исследование закономерностей формирования структуры пористого кремния при многостадийных режимах электрохимического травления // Известия СПбГЭТУ ЛЭТИ, 2011(4), с. 3-9.
10. Белорус А. О., Комлев А. А. Свидетельство о государственной регистрации программы для ЭВМ №2014613394. Measurement of contact angle (MofCA) 26 марта 2014 г.

11. Van Hoonacker A., Englebienne P. Revisiting silver nanoparticle chemical synthesis and stability by optical spectroscopy // Current Nanoscience, 2006, v. 2(4), pp. 359-371. DOI: 10.2174/157341306778699 310

12. Гирель К. В., Бондаренко А. В. Формирование наноструктур серебра методом иммерсионного осаждения // Доклады БГУИР, 2014, т. 86(8), c. 5-10.

UDC 538.9

DOI: $10.17308 / \mathrm{kcmf} .2019 .21 / 1158$

Received 27.06.2019

Accepted 15.09.2019

\title{
FEATURES OF SILVER DEPOSITION IN POROUS SILICON BY ELECTRO-THERMAL DIFFUSION METHOD
}

\author{
(ㄷ 2019 V. L. Koshevoy ${ }^{1}$, A. O. Belorus², L. B. Matyushkin ${ }^{2}$, I. M. Pleshanov ${ }^{3}$, P. V. Seredin ${ }^{4}$, \\ S. A. Ivkov ${ }^{4}$ A. S. Lenshin \\ ${ }^{1}$ Saint-Petersburg Mining University \\ 2, 21st Line, 199106 St. Petersburg, Russian Federation \\ ${ }^{2}$ Saint Petersburg Electrotechnical University "LETI" \\ 5, Professora Popova str., 197376 St. Petersburg, Russian Federation \\ ${ }^{3}$ Saint Petersburg National Research University of Information Technologies, Mechanics and Opticsc (ITMO) \\ 49, Kronverksky pr., 197101 St. Petersburg, Russian Federation \\ ${ }^{4}$ Voronezh State University \\ 1, Universitetskaya pl., 394018 Voronezh, Russian Federation
}

\begin{abstract}
Purpose. In this work, we investigated the possibility of modifying porous silicon with silver particles.

Methods and methodology. For the synthesis of substrates was used the method of electrochemical etching in hydrofluoric acid solutions. At given technological parameters was formed a porous matrix. The resulting samples were subjected to further functionalization. For the synthesis of silver ink $\mathrm{AgNO}_{3}$ was used the method of colloidal quantum dots and then by the method of electro-thermal diffusion, these particles were deposited in a porous matrix to forming a composite structure. To study the samples was used by scanning electron microscopy. Morphology and diffusion processes were studied using SEM data. To control the functionalization process was used the method of determining the wetting angle.

Results. Using the method of centrifugation, a silver layer was deposited on a porous silicon matrix. According to SEM data, it was established that the pore size is $d=50-100 \mathrm{~nm}$, the layer thickness is $25 \mu \mathrm{m}$. Base on wetting angle data was concluded that the porous silicon matrix is initially hydrophobic $\left(\theta \approx 59^{\circ}\right)$. After the deposition of silver particles, the hydrophobicity changes to hydrophilicity $\left(\theta \approx 31^{\circ}\right)$ and further electrothermal effects have little effect on the wetting angle and the nature of hydrophilicity $\left(\theta \approx 42^{\circ}\right)$.

Conclusion. As a result of research work demonstrated the effectiveness of the electro-thermal methods for introducing silver into the porous silica matrix. It shows that the deposition of silver leads to a decrease in the hydrophobicity of the surface.
\end{abstract}

$\triangle$ Lenshin Alexander S., e-mail: lenshinas@phys.vsu.ru 
Keywords: silicon, porous silicon, composite structures, functionalization, electro-thermal diffusion, wetting angle.

\section{SOURCE OF FINANCING}

The study was carried out with the support of the Russian Foundation for Basic Research in the framework of the scientific project 19-32-50038 mol_nr "Study of the morphological, physicochemical and optical properties of por-Si depending on the methods of their formation and functionalization”.

\section{CONFLICT OF INTEREST}

The authors declare the absence of obvious and potential conflicts of interest related to the publication of this article.

\section{REFERENCES}

1. Raúl J. Martín-palma, Patrick D. McAtee, Rehab Ramadan, Akhlesh Lakhtakia. Hybrid nanostructured porous silicon-silver layers for wideband optical absorption. Scientific Reports, 2019, v. 9(1), p. 7291. DOI: 10.1038/s41598-019-43712-7

2. Kleps I., Miu M., Danila M., Simion M., Ignat T., Bragaru A., Dumitru L., Teodosiu G. Silver/porous silicon (PS) nanocomposite layers for biomedical applications. Proc. of "2006 International Semiconductor Conference”, 27-29 Sep., 2006, no. 9211112. DOI: 10.1109/SMICND.2006.283935

3. Ensafi A. A., Rezaloo F., Rezaei B. Electrochemical sensor based on porous silicon/silver nanocomposite for the determination of hydrogen peroxide. Sensors and Actuators B, 2016, v. 231, pp. 239-244. DOI: 10.1016/j.snb.2016.03.018

4. Jinjie Yin, Xiang Qi, Liwen Yang, Guolin Hao, Jun Li, Jianxin Zhong A hydrogen peroxide electrochemical sensor based on silver nanoparticles decorated silicon nanowire arrays. Electrochimica Acta, 2011, v. 56(11), pp. 3884-3889. DOI: 10.1016/j.electacta.2011.02.033

5. Spivak Yu. M., Bespalova K. A., Belorus A. O., Panevin A. A., Somov P. A., Grigor'eva N. Yu., Chistyakova L. V., Zhuravskiy S. G., Moshnikov V. A. Sposob polucheniya i primer lekarstvennoy funktsionalizatsii poverkhnosti nanochastits poristogo kremniya [A method of obtaining and an example of drug functionalization of the surface of porous silicon nanoparticles]. Biotekhnosfera [Biotechnosphere], 2017 (3), pp. 69-75. (in Russ.)
6. Pastukhov A. I., Belorus A. O., Bukina Ya. V., Spivak Yu. M., Moshnikov V. A. Influence of technology conditions on the surface energy of porous silicon using the method of contact angle. Proc. of "2017 IEEE Conference of Russian Young Researchers in Electrical and Electronic Engineering (EIConRus)", 1-3 Feb., 2017, pp. 1183-1185. DOI: 10.1109/eiconrus.2017.7910770

7. Matyushkin L. B. Tekhnologiya i oborudovanie dlya polucheniya kolloidnykh kvantovykh tochek $\mathrm{CsPbX}_{3}(\mathrm{X}=\mathrm{Cl}, \mathrm{Br}, \mathrm{I})$, CdSe/ZnS, plazmonnykh nanochastits $\mathrm{Ag} / \mathrm{SiO}_{2}$ i gibridnykh struktur na ikh osnove [Technology and equipment for obtaining $\mathrm{CsPb}_{3}$ colloidal quantum dots $(\mathrm{X}=\mathrm{Cl}, \mathrm{Br}, \mathrm{I}), \mathrm{CdSe} / \mathrm{ZnS}, \mathrm{Ag} / \mathrm{SiO}_{2}$ plasmonic nanoparticles and hybrid structures based on them. Cand. Sci. (Eng.) diss. St. Petersburg, 2018, 138 p. URL: https://elibrary.ru/item.asp?id=35115356 (in Russ.)

8. Permiakov N.V., Matyushkin L. B., Belorus A. O., Koshevoi V. L. Investigation of a program-controlled process of impregnation of porous semiconductors with silver nanoparticles to create an electrical contact. Proc. of "IEEE Conference of Russian Young Researchers in Electrical and Electronic Engineering (EIConRus)", 2018, pp. 539-543. DOI: 10.1109/EIConRus.2018.8317154

9. Travkin P. G., Vorontsova N. V., Vysotsky S. A., Lenshin A. S., Spivak Yu. M., Moshnikov V. A. Issledovanie zakonomernostey formirovaniya struktury poristogo kremniya pri mnogostadiynykh rezhimakh elektrokhimicheskogo travleniya [Study of regularities of porous silicon structure formation with multistage modes of electrochemical etching]. Izvestiya SPBGETU LETI, 2011(4). pp. 3-9. (in Russ.)

10. Belorus A. O., Komlev A. A. Certificate of state registration of computer programs No. 2014613394. Measurement of contact angle (MofCA) 26 March 2014. (in Russ.)

11. Van Hoonacker A., Englebienne P. Revisiting silver nanoparticle chemical synthesis and stability by optical spectroscopy. Current Nanoscience, 2006, v. 2(4), pp. 359-371. DOI: 10.2174/157341306778699310

12. Girel K. V., Bondarenko A. V. Formirovanie nanostruktur serebra metodom immersionnogo osazhdeniya [Formation of silver nanostructures by immersion deposition method onto porous silicon and study of their optical properties]. Doklady BGUIR, 2014, v. 86(8), pp. 5-10. (in Russ.) 
Кошевой Вениамин Леонович - аспирант, Санкт-Петербургский горный университет, Санкт-Петербург, Российская Федерация; e-mail: venia.koshevoi.eltech@gmail.com.ORCIDiD 00000001-5958-0319.

Белорус Антон Орестович - аспирант, СанктПетербургский государственный электротехнический университет «ЛЭТИ» им. В.И. Ульянова (Ленина) (СПбГЭТУ «ЛЭТИ»), Санкт-Петербург, Российская Федерация; e-mail: mop_92@mail. ru. ORCID iD 0000-0002-6752-8796.

Матюшкин Лев Борисович - к. т. н., с. н. с., Санкт-Петербургский государственный электротехнический университет «ЛЭТИ» им. В. И. Ульянова (Ленина) (СПбГЭТУ «ЛЭТИ»), Санкт-Петербург, Российская Федерация; e-mail: leva. matyushkin@gmail.com.ORCID iD 0000-00031232-5358.

Плешанов Илья Михайлович - аспирант, Санкт-Петербургский национальный исследовательский университет информационных технологий, механики и оптики, Санкт-Петербург, Российская Федерация; e-mail:pim93@mail.ru

Середин Павел Владимирович - д. ф.-м.н., доцент, кафедра физики твердого тела и наноструктур, Воронежский государственный университет, Воронеж, Российская Федерация; e-mail:paul@ phys.vsu.ru. ORCIDiD 0000-0002-6724-0063.

Ивков Сергей Александрович - аспирант, ведущий инженер, Воронежский государственный университет, Воронеж, Российская Федерация; e-mail: ivkov@phys.vsu.ru. ORCID iD 00000003-1658-5579.

Леньшин Александр Сергеевич - к. ф.-м. н., с. н. с.,Воронежский государственный университет, Воронеж, Российская Федерация; e-mail: lenshinas@mail.ru.ORCID iD 0000-0002-1939253X.
Koshevoi Veniamin L. - postgraduate, Saint Petersburg Mining University, St. Petersburg, Russian Federation;e-mail: venia.koshevoi.eltech@gmail. com. ORCID iD 0000-0001-5958-0319.

Belorus Anton O. - postgraduate, Saint Petersburg Electrotechnical University “LETI”, St. Petersburg, Russian Federation; e-mail:mop_92@mail.ru. ORCIDiD 0000-0002-6752-8796.

Matyushkin Lev B. - Cand. Sc. (Eng.), Senior Researcher, Saint Petersburg Electrotechnical University “LETI", St. Petersburg, Russian Federation; e-mail: leva.matyushkin@gmail.com. ORCIDiD 0000-0003-1232-5358.

Pleshanov Ilya M. - postgraduate, Saint Petersburg National Research University of Information Technologies, Mechanics and Opticsc (ITMO), St. Petersburg, Russian Federation; e-mail: pim93@ mail.ru

SeredinPavel V. - Dr. Sci. (Phys.-Math.), Associate Professor, Department of Solid State Physic and Nanostructures, Voronezh State University, Voronezh, Russian Federation; e-mail: paul@phys.vsu. ru. ORCIDiD 0000-0002-6724-0063.

Ivkov Sergey A. - postgraduate, Leading Engineer, Voronezh State University, Voronezh, Russian Federation; e-mail: ivkov@phys.vsu.ru.ORCID iD 0000-0003-1658-5579.

Lenshin Alexander S. - Cand. Sci. (Phys.-Math.), Senior Researcher, Voronezh State University, Voronezh, Russian Federation; e-mail: lenshinas@ mail.ru. ORCIDiD 0000-0002-1939-253X. 